\title{
Article \\ Observations of a Coniferous Forest at 9.6 and 17.2 GHz: Implications for SWE Retrievals
}

\author{
Aaron Thompson *(D) and Richard Kelly \\ Department of Geography \& Environmental Management, University of Waterloo, Waterloo, ON N2L 3G1, \\ Canada; rejkelly@uwaterloo.ca \\ * Correspondence: aaron.thompson@uwaterloo.ca; Tel.: +1-519-888-4567 (ext. 31322)
}

Received: 13 November 2018; Accepted: 18 December 2018; Published: 20 December 2018

\begin{abstract}
UWScat, a ground-based Ku- and X-band scatterometer, was used to compare forested and non-forested landscapes in a terrestrial snow accumulation environment as part of the NASA SnowEx17 field campaign. Field observations from Trail Valley Creek, Northwest Territories; Tobermory, Ontario; and the Canadian Snow and Ice Experiment (CASIX) campaign in Churchill, Manitoba, were also included. Limited sensitivity to snow was observed at $9.6 \mathrm{GHz}$, while the forest canopy attenuated the signal from sub-canopy snow at $17.2 \mathrm{GHz}$. Forested landscapes were distinguishable using the volume scattering component of the Freeman-Durden three-component decomposition model by applying a threshold in which values $\geq 50 \%$ indicated forested landscape. It is suggested that the volume scattering component of the decomposition can be used in current snow water equivalent (SWE) retrieval algorithms in place of the forest cover fraction $(F F)$, which is an optical surrogate for microwave scattering and relies on ancillary data. The performance of the volume scattering component of the decomposition was similar to that of $F F$ when used in a retrieval scheme. The primary benefit of this method is that it provides a current, real-time estimate of the forest state, it automatically accounts for the incidence angle and canopy structure, and it provides coincident information on the forest canopy without the use of ancillary data or modeling, which is especially important in remote regions. Additionally, it enables the estimation of forest canopy transmissivity without ancillary data. This study also demonstrates the use of these frequencies in a forest canopy application, and the use of the Freeman-Durden three-component decomposition on scatterometer observations in a terrestrial snow accumulation environment.
\end{abstract}

Keywords: radar scatterometer; snow; SWE retrieval; Freeman-Durden 3-component decomposition

\section{Introduction}

Snow is a critical component in the Earth's hydrologic cycle and energy balance, as well as a source of fresh water for human consumption [1]. More than one-sixth of the global population depends on this water, but its availability is changing with changes to our climate [2]. Given the importance of snow and the predicted changes in its accumulation [3-6], it is important to monitor; yet, understanding these changes is difficult due to inter-annual variability, inadequate remote sensing products, and poor snow records throughout most of the world [1]. The last two points are unequivocally linked.

Remote sensing approaches to estimate regional-to-global snow accumulation at a high level of accuracy are not available from satellites or from routine airborne observations. However, radar observations have the potential to provide snowpack information, especially the snow water equivalent (SWE), globally and in a timely manner for effective water resource management, although this approach has yet to be proven. In situ and limited airborne Ku-band observations of snow have demonstrated sensitivity to the SWE at the local scale with Ku-band backscatter sensitivity to the SWE showing strong signature sensitivity in different environments with applicability for the modeling 
of radar response [7-10]. Synthetic aperture radar (SAR) imaging can provide wintertime landscape observations at spatial resolutions $<100 \mathrm{~m}$, which makes it an attractive technique for snow mapping.

Current methods for estimating the SWE at $\mathrm{Ku}$ - and $\mathrm{X}$-band frequencies focus on moderate-to-shallow snow and include that proposed by [7] for the CoReH20 mission and that proposed by [11], which uses an interferometric approach; other recent work has been done by [12-14]. However, these studies have excluded forested regions and, therefore, have neglected the sub-canopy SWE. This is unsurprising, because forested regions are among the most challenging environments for remote sensing of snow [15]. Of particular relevance in Canada, the boreal forest, dominated by coniferous species and situated in the circumpolar northern high latitudes, covers 270 million ha, or about $30 \%$ of the landscape [16]. Globally, boreal forest covers 1.1 billion ha and is the Earth's largest terrestrial ecosystem [15]. Given the northern locale and the intersection of the boreal zone with snow-covered landscapes [17], it is important that the estimation of the SWE accounts for forest attenuation of the snow backscatter signal.

Recent studies on SWE retrieval from boreal environments typically rely on ancillary data, allometric relationships, or forest modeling to delineate forested areas and provide the necessary parameters, such as the forest cover fraction (FF) and transmissivity [18-22]. However, ancillary data becomes outdated quickly, allometric relationships tend to be regionally specific, and forest models add complexity to SWE retrieval. Moreover, forestry applications of radar typically utilize C-, L-, and P-band radar (e.g., [23-25]) for their penetration capabilities with respect to biomass retrieval, while there are limited forest studies focused on X-band and fewer focusing on Ku-band; thus, questions remain as to the influence of forest, particularly in the context of SWE retrieval. Therefore, in this study, the $\mathrm{Ku}$ - and $\mathrm{X}$-band radar signature from a coniferous forest (herein referred to as forest) in a terrestrial snow accumulation environment was explored to quantify its effect on the radar response at Ku- and $X$ - band frequencies. Three questions are addressed: First, what is the polarimetric radar response to forest vegetation in a snow accumulation environment; second, is there a distinctive Ku-band and $\mathrm{X}$-band radar response that can distinguish a forested terrain; and third, how could these observations be applied to improve current SAR retrieval of the SWE in a forested environment? In addressing these objectives, this study uses the Freeman-Durden three-component decomposition on scatterometer observations to interpret the $\mathrm{Ku}-(17.2 \mathrm{GHz})$ and $\mathrm{X}$-band $(9.6 \mathrm{GHz})$ radar response from a terrestrial snow accumulation environment.

\subsection{Radar Response to Forest}

The inhomogeneous, anisotropic nature of the forest canopy adds complexity to the interpretation of microwave scattering, which, as shown in Figure 1, consists of different mechanisms: (1) scattering direct from underlying ground, (2) specular scattering from ground-trunk interactions, (3) scattering from the canopy, and (4) ground-canopy interactions, where all the terms may be attenuated from transmission through the upper layers [23,24,26,27]. Scattering of wavelengths at C-band or higher frequencies ( $\mathrm{X}$ - or Ku-band) is dominated by the canopy and consists of scattering from canopy elements, such as needles, twigs, and branches [24,25].

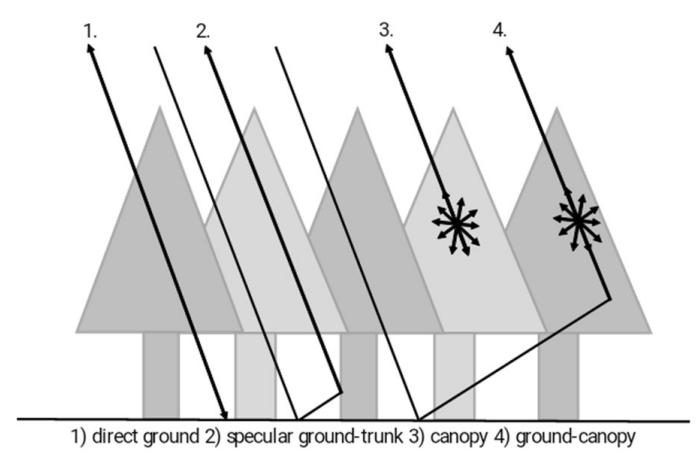

Figure 1. Scattering mechanisms of forests. 
Radar backscatter is primarily controlled by structural attributes of the forest and tends to saturate at levels of biomass that scale with wavelength [28]. For this reason, longer wavelengths, such as Land P-band are preferred in biomass studies and have been used to successfully delineate forested landscapes (e.g., [26,29-31]. These frequencies also have sensitivity to biomass from the entire tree and not just the canopy. However, they are not sensitive to terrestrial snow accumulation, unlike Ku- and $\mathrm{X}$-band. Yet Ku- and X-band have weaker penetration capabilities in forested environments, losing sensitivity at much lower levels of biomass with the response originating primarily from upper canopy elements; Montomoli et al. [22] found that $83 \%$ and $39 \%$ of the $\mathrm{Ku}$ - and X-band responses to a coniferous canopy, respectively, originated from the needles. Despite the limited penetration capabilities of these frequencies, this study aims to demonstrate how $\mathrm{Ku}$ - and X-band radar scatterometer observations can be used to distinguish forested from non-forested landscapes and can provide biomass-related information for SWE retrievals.

\subsection{SWE Retrievals in Forested Landscapes}

Recent radar-based SWE retrieval algorithms for use in forested regions have been developed through the CoReH20 framework of [7] (e.g., [18,21,22,32]). These models rely on parameters linked to biomass, such as the $F F$ and two-way transmissivity to scale backscatter from the sub-canopy environment. Such parameters are sourced from $a$ priori ancillary information (e.g., traditional forest inventories and active and passive optical datasets), modeled estimates, and allometric relationships, but there are considerable limitations associated with these approaches. A priori information, such as forest inventories, can quickly become outdated due to growth and abrupt landscape change or be unavailable, as [24] found. Allometry is regional in nature necessitating local relationships [28], which may be unavailable, especially in remote regions. Modeled estimates can be prohibitive due to their complexity, the number of inputs required (e.g., geometrical description of leaves, branches, trunks, density, and $F F$ ), and the mis-match of the required inputs and available data [22]. The inversion of such models is often impossible, given the large number of inputs required and the limited outputs in the forward model [33]. Furthermore, estimates of $F F$ and transmissivity are sensitive to the incidence angle and forest architecture, which necessitate a detailed geometrical description of the canopy. This is challenging on a local scale and impractical on a global one. A final drawback of using the $F F$ in this application is that it is based on optical scattering yet is intended for use in a microwave scattering model, and so, it provides a less appropriate description of the forest canopy. A simpler method is proposed that uses the volume scattering proportion $\left(V_{F D}\right)$ from the Freeman-Durden three-component decomposition and does not require ancillary data, forest models, or allometric relationships yet is sensitive to the influence of the incidence angle and forest architecture. A number of studies have employed model-based polarimetric decompositions, such as the Freeman-Durden three-component decomposition to identify the dominant scattering mechanisms of complex natural and man-made targets. Such studies have often aimed to distinguish land cover types and have demonstrated sensitivity to forested landscapes [31,33-38]; however, these studies employed C-, L- and P-band data.

\section{Study Location and Site Description}

The observations in this study were collected from 22 sites, spanning four field campaigns and seven years. Forested and non-forested sites were observed on Grand Mesa, CO, in February 2017, as part of the NASA SnowEx 2017 field campaign [39] and from Trail Valley Creek (TVC), NT in April 2017. Forested sites were observed in Churchill, MB, during the winter of 2010/2011, as part of the Canadian Snow and Ice Experiment (CASIX), and in Tobermory, ON, during the winter of 2013/2014. See Figure 2 for the site locations and Figure 3 for photographs of each forested site.

Grand Mesa is a large, flat-topped mountain located in western Colorado with a yearly average maximum air temperature of $7.8^{\circ} \mathrm{C}$ and an annual snowfall of over $9 \mathrm{~m}$ [40]. The study sites were situated at about $39.0395^{\circ} \mathrm{N}, 107.9417^{\circ} \mathrm{W}$ with an elevation of $3176 \mathrm{~m}$ above sea level (a.s.l.). The non-forested sites were primarily flat, grassy meadowland, while the forested site was comprised 
of Engelmann spruce ranging in height from $1 \mathrm{~m}$ to $9 \mathrm{~m}$. The soils consisted of gravelly loam over bedrock [41]. The forested observations were made from an elevated platform.

TVC is located $50 \mathrm{~km}$ north of Inuvik, NT, at $68.7462^{\circ} \mathrm{N}, 133.5022^{\circ} \mathrm{W}$ and $50-180 \mathrm{~m}$ a.s.1. The annual average air temperature is $-8.2^{\circ} \mathrm{C}$, and it receives about $159 \mathrm{~cm}$ of snowfall annually [42]. The vegetation is primarily grass, lichens, and mosses with alder, birch, willow, and black spruce found on hillslopes and in valley bottoms [43]. The terrain is hummocky, and the soils consist of peat and silty clay soil over permafrost [44]. The non-forested sites consisted of open tundra, while the forested site consisted of black spruce ranging from 0.6 to $3 \mathrm{~m}$ in height. All the observations were ground-based.

Churchill is situated on the western shore of the Hudson Bay near the Churchill River. The yearly average air temperature is $-6.5^{\circ} \mathrm{C}$, and it receives about $201 \mathrm{~cm}$ of snowfall annually [45]. The study site is located at approximately $58.7299^{\circ} \mathrm{N}, 93.8203^{\circ} \mathrm{W}$ and $29 \mathrm{~m}$ a.s.1., near the tree line on organic soils over permafrost $[9,46]$. The radar observations were made of a black spruce forest and taiga snow environment from an elevated platform; the trees ranged in height to a maximum of about $15 \mathrm{~m}$.

Tobermory is situated on the Niagara Escarpment, at the northern edge of the Bruce Peninsula, at about $45.2573^{\circ} \mathrm{N}, 81.6561^{\circ} \mathrm{W}$ and $213.4 \mathrm{~m}$ a.s.1. The region has a yearly average air temperature of $6.6^{\circ} \mathrm{C}$ and receives about $405 \mathrm{~cm}$ of snowfall annually [47]. Radar observations were made from an observation tower over a mature mixed species forest, which included eastern white cedar, white spruce, and white birch. The tree height was approximately $15 \mathrm{~m}$. The soils consist of sandy loam over exposed bedrock [48].
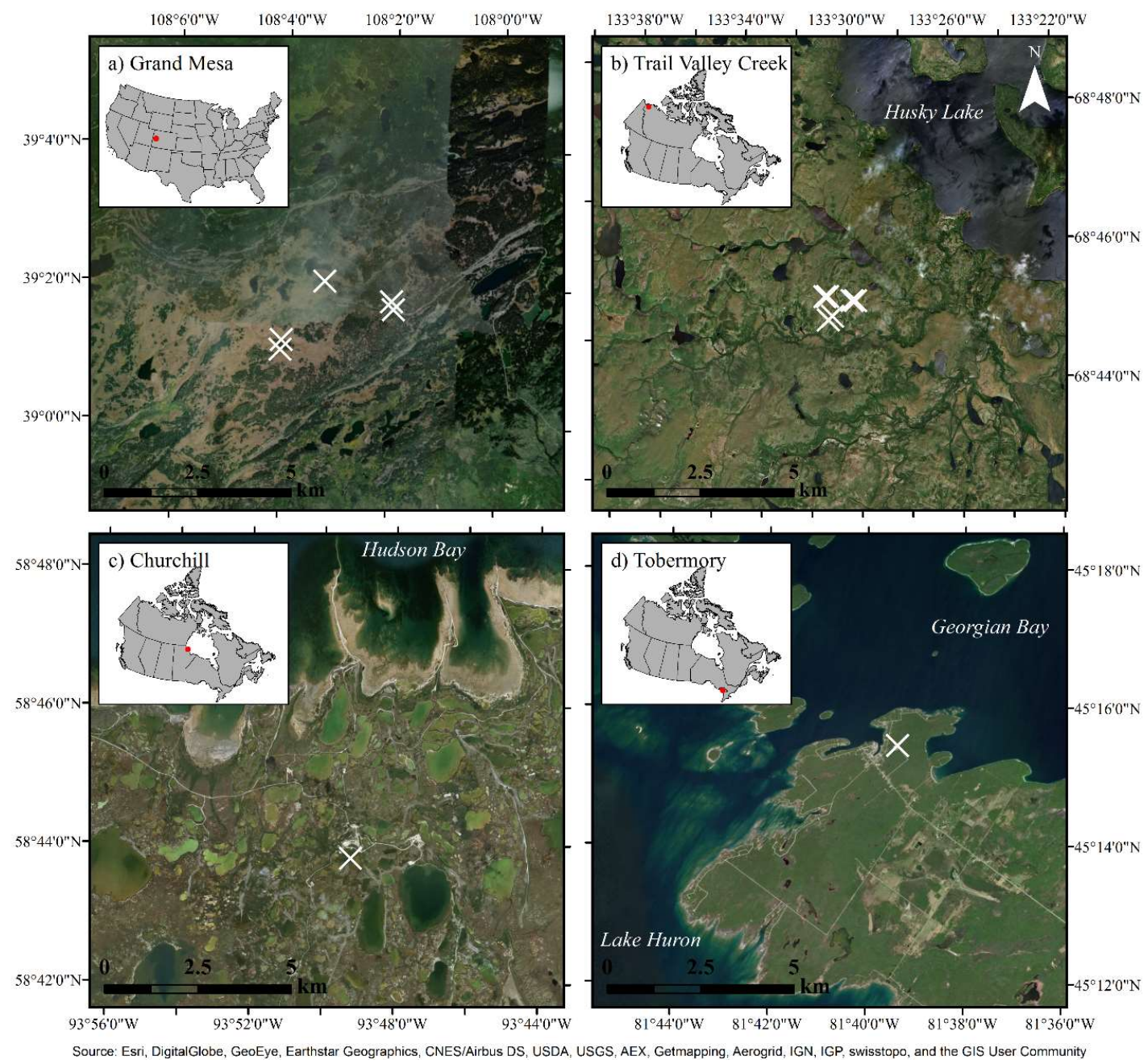

Figure 2. Site locations in Grand Mesa: (a) Colorado, (b) Trail Valley Creek, Northwest Territories, (c) Churchill, Manitoba, and (d) Tobermory, Ontario. 

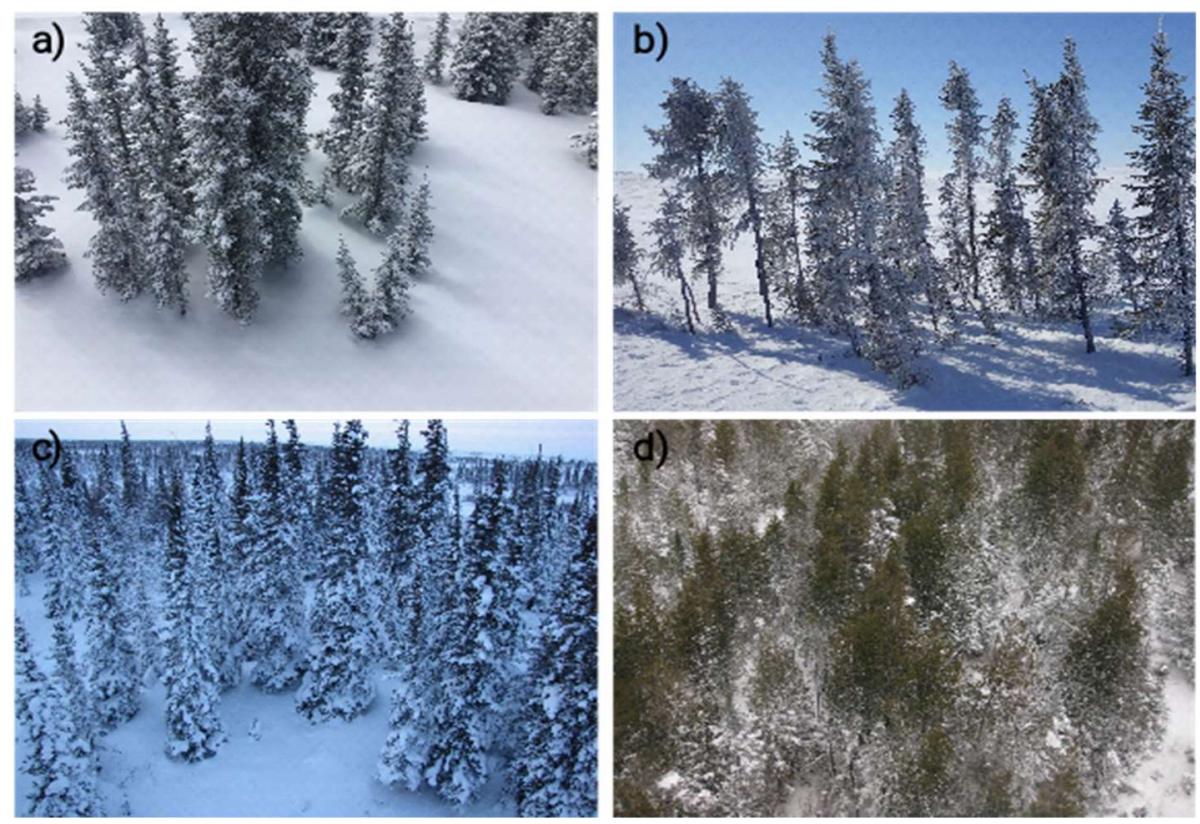

Figure 3. Forested sites at (a) Grand Mesa, (b) Trail Valley Creek, (c) Churchill, and (d) Tobermory.

The air temperatures during the acquisition periods at each site are provided in Figure 4. The observations were generally made during periods of cold, dry weather, with the exception of those made in Tobermory on 31 March, 7 May, and 22 May (sites 18, 19, and 22), during which time the air temperatures were above $0{ }^{\circ} \mathrm{C}$.

A summary description of each observation site is provided in Table 1 and includes bulk snowpack properties. The snow depth in the non-forested sites ranged from $33 \mathrm{~cm}$ to $205 \mathrm{~cm}$, corresponding to SWE values of $121 \mathrm{~mm}$ to $675 \mathrm{~mm}$. The snow depth in the forested sites ranged from $21 \mathrm{~cm}$ to $83 \mathrm{~cm}$, corresponding to SWE values of $38 \mathrm{~mm}$ to $202 \mathrm{~mm}$, although in situ measurements of snow were not made within the forested sites on Grand Mesa, where the deepest, non-forested snow was found; it is expected that the forested sites on Grand Mesa (sites 14 and 15) had depths at least as great as the adjacent non-forested site (site 5). Snow density ranged from $159 \mathrm{~kg} / \mathrm{m}^{3}$ in the taiga forests of Churchill to $416 \mathrm{~kg} / \mathrm{m}^{3}$ in the wind slab-dominated tundra drifts of TVC.
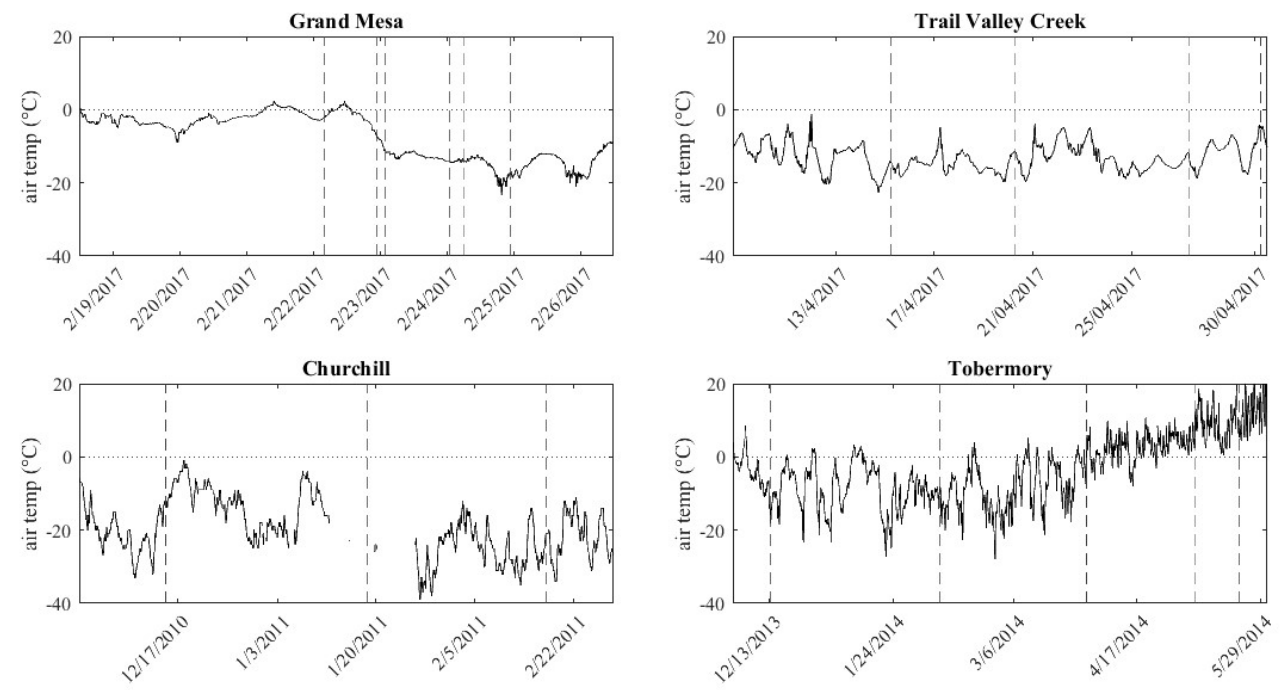

Figure 4. The air temperatures during the observation periods. The vertical lines denote observations. 
Table 1. Summary of UWScat observation parameters and bulk snowpack properties.

\begin{tabular}{|c|c|c|c|c|c|c|c|c|c|c|c|c|c|}
\hline \multicolumn{4}{|c|}{ Site Description } & \multicolumn{5}{|c|}{ UWScat Observation Parameters } & \multicolumn{4}{|c|}{ Bulk Snowpack Properties } & \multirow[b]{2}{*}{ Notes } \\
\hline Site no. & Class & Site & Date & $\begin{array}{l}\text { Azimuth } \\
\text { Sweep }\end{array}$ & $\begin{array}{l}\text { Incidence } \\
\text { Angle } \\
\text { Range }\end{array}$ & $\begin{array}{l}\text { Incidence } \\
\text { Angle } \\
\text { Step }\end{array}$ & $\begin{array}{c}\text { Antenna } \\
\text { Height }^{\mathrm{a}} \\
\text { (m) }\end{array}$ & $\begin{array}{l}\text { Depth } \\
(\mathrm{cm})\end{array}$ & $\begin{array}{l}\text { Density } \\
\left(\mathrm{kg} / \mathrm{m}^{3}\right)\end{array}$ & $\begin{array}{l}\text { SWE } \\
\text { (mm) }\end{array}$ & $\begin{array}{c}\text { Depth } \\
\text { Hoar (\%) }\end{array}$ & $\begin{array}{l}\text { Wind } \\
\text { Slab (\%) }\end{array}$ & \\
\hline 1 & non-forest & Grand Mesa & $22 / 02 / 17$ & $30^{\circ},-30^{\circ}$ & $25^{\circ}, 62^{\circ}$ & $3^{\circ}$ & 2.1 & 178 & 319 & 568 & na & na & \\
\hline 3 & non-forest & Grand Mesa & $23 / 02 / 17$ & $30^{\circ},-30^{\circ}$ & $25^{\circ}, 62^{\circ}$ & $3^{\circ}$ & 2.1 & na & na & na & na & na & \\
\hline 4 & non-forest & Grand Mesa & $24 / 02 / 17$ & $30^{\circ},-30^{\circ}$ & $25^{\circ}, 62^{\circ}$ & $3^{\circ}$ & 2.0 & 180 & 300 & 540 & 0 & 0 & \\
\hline 5 & non-forest & Grand Mesa & $25 / 02 / 17$ & $-10^{\circ},-40^{\circ}$ & $25^{\circ}, 65^{\circ}$ & $3^{\circ}$ & 9.5 & 205 & 329 & 675 & 3 & 0 & Skyjack, trees within FOV \\
\hline $6^{\mathrm{d}}$ & non-forest & Trail Valley & $15 / 04 / 17$ & $20^{\circ}, 80^{\circ}$ & $25^{\circ}, 62^{\circ}$ & $3^{\circ}$ & 2.1 & 62 & 308 & 110 & 35 & 37 & gap in snowpack below $17 \mathrm{~cm}$ \\
\hline 7 & non-forest & Trail Valley & $20 / 04 / 17$ & $30^{\circ}, 90^{\circ}$ & $25^{\circ}, 62^{\circ}$ & $3^{\circ}$ & 2.1 & 92 & 416 & 137 & 27 & 53 & drift, large alder shrub buried in FOV \\
\hline 8 & non-forest & Trail Valley & $20 / 04 / 17$ & $30^{\circ},-30^{\circ}$ & $25^{\circ}, 62^{\circ}$ & $3^{\circ}$ & 2.1 & 90 & 356 & 192 & 18 & 54 & drift, adjacent to 7 \\
\hline 9 & non-forest & Trail Valley & $27 / 04 / 17$ & $20^{\circ}, 80^{\circ}$ & $25^{\circ}, 62^{\circ}$ & $3^{\circ}$ & 2.1 & 0 & 0 & 0 & 0 & 0 & same as 6 , all snow removed from FOV \\
\hline 10 & non-forest & Trail Valley & $30 / 04 / 17$ & $30^{\circ},-30^{\circ}$ & $25^{\circ}, 62^{\circ}$ & $3^{\circ}$ & 2.0 & 33 & 368 & 55 & 42 & 24 & \\
\hline 11 & forested & Churchill & $15 / 12 / 10$ & $30^{\circ},-30^{\circ}$ & $21^{\circ}, 81^{\circ}$ & $3^{\circ}$ & 10.2 & 21 & 183 & 28 & 58 & 0 & Skyjack \\
\hline 12 & forested & Churchill & $18 / 01 / 11$ & $30^{\circ},-30^{\circ}$ & $21^{\circ}, 81^{\circ}$ & $3^{\circ}$ & 10.2 & 28 & 159 & 33 & 38 & 0 & Skyjack \\
\hline 13 & forested & Churchill & $17 / 02 / 11$ & $30^{\circ},-30^{\circ}$ & $21^{\circ}, 81^{\circ}$ & $3^{\circ}$ & 10.2 & 39 & 174 & 67 & 45 & 0 & Skyjack \\
\hline 14 & forested & Grand Mesa & $24 / 02 / 17$ & $30^{\circ},-30^{\circ}$ & $25^{\circ}, 65^{\circ}$ & $3^{\circ}$ & 9.9 & na & na & na & na & na & Skyjack \\
\hline 15 & forested & Grand Mesa & $25 / 02 / 17$ & $20^{\circ},-10^{\circ}$ & $25^{\circ}, 65^{\circ}$ & $3^{\circ}$ & 9.5 & na & na & na & na & na & Skyjack \\
\hline 16 & forested & Tobermory & $13 / 12 / 13$ & $30^{\circ},-30^{\circ}$ & $35^{\circ}, 70^{\circ}$ & $5^{\circ}$ & 22.2 & 21 & na & 66 & na & na & observation platform \\
\hline $17^{\mathrm{e}}$ & forested & Tobermory & $09 / 02 / 14$ & $30^{\circ},-30^{\circ}$ & $35^{\circ}, 70^{\circ}$ & $5^{\circ}$ & 22.2 & 50 & 246 & 118 & 0 & 0 & observation platform \\
\hline 18 & forested & Tobermory & $31 / 03 / 14$ & $30^{\circ},-30^{\circ}$ & $35^{\circ}, 70^{\circ}$ & $5^{\circ}$ & 22.2 & 46 & na & 115 & na & na & observation platform \\
\hline 19 & forested & Tobermory & $22 / 05 / 14$ & $30^{\circ},-30^{\circ}$ & $35^{\circ}, 60^{\circ}$ & $5^{\circ}$ & 22.2 & 0 & 0 & 0 & 0 & 0 & observation platform \\
\hline $20^{\mathrm{d}}$ & forested & Trail Valley & $15 / 04 / 17$ & $20^{\circ},-40^{\circ}$ & $25^{\circ}, 62^{\circ}$ & $3^{\circ}$ & 2.1 & 83 & 284 & 145 & 36 & 10 & adjacent to 6 , branch gaps in snowpack \\
\hline
\end{tabular}

a antenna height at full vertical extension equivalent to a $90^{\circ}$ incidence angle $\mathrm{b}$ instrument mounted on top of a 0.9 -m snowpack observing a snow-excavated field of view (FOV) giving an antenna height of $3.0 \mathrm{~m} ;{ }^{\mathrm{c}}$ X-band only; ${ }^{\mathrm{d}}$ snowpit completed on 25/04/17; ${ }^{\mathrm{e}}$ snowpit completed on 27/01/14. SWE: snow water equivalent. 


\section{Field Observations and Methods}

UWScat is a dual frequency Ku- and X-band scatterometer system operating at center frequencies of $17.2 \mathrm{GHz}$ and 9.6 GHz, respectively. King et al. [8] provide a full description of the system, and Table 2 shows the principle system parameters. The scatterometer calibration was achieved with an internal procedure, which uses a delay line calibration loop to account for gain variations due to temperature fluctuation, and an external procedure using an in-scene trihedral calibration target to generate the transmitter distortion matrix. An unobstructed sky observation was employed to characterize transmitter leakage, and a near-field gain correction described by [49] was applied when the target was within the antenna's far-field distance $(<5.4 \mathrm{~m}$ at $17.2 \mathrm{GHz}$ and $<17.1 \mathrm{~m}$ at $9.6 \mathrm{GHz})$. The instrument was tripod-mounted with the antenna positioned $\sim 2 \mathrm{~m}$ above the snow surface for near-ground deployments, at $\sim 10 \mathrm{~m}$ above ground on a Skyjack platform, and $\sim 22 \mathrm{~m}$ above ground on an observation tower. The radar observations in Churchill and Tobermory were taken from the same position over different dates. Efforts were made to ensure that the positional accuracy was maintained on each deployment. This revisit scheme was necessitated by logistical constraints, which limited the opportunities to deploy UWScat at elevations above the forest canopy in these particular environments. Similarly, the forested sites on Grand Mesa were also revisited (see sites 14 and 15 in Table 1) although these observations were azimuthally offset by $10^{\circ}$ and, therefore, capture a different perspective of the same forest. At TVC, only sites 6 and 9 were revisited (see sites 20 and 21 in Table 1), but the snow was removed before the second set of radar observations. The observation parameters employed in this study were variable and are summarized in Table 1 along with the bulk snowpack properties for all the observations. In all cases, except sites 9, 19, 21, and 22, there was snow accumulation present. Sites 19 and 22 were observed in May, so no snow was present, and air temperatures were warm. In each case, the normalized radar cross section $\left(\sigma^{\circ}\right)$ and polarimetric parameters were derived by averaging the independent samples within each azimuth sweep over a homogeneous target. This procedure improves measurement precision and minimizes the effects of radar fade.

Table 2. UWScat system parameters.

\begin{tabular}{ccc}
\hline Parameter & $\mathbf{K u}$ & $\mathbf{X}$ \\
\hline Output frequency $(\mathrm{GHz})$ & $16.95-17.45$ & $9.35-9.85$ \\
Center frequency $(\mathrm{GHz})$ & 17.2 & 9.6 \\
Transmit power, narrow beam $(\mathrm{dBm})$ & -8 & -11.8 \\
Transmit bandwidth $(\mathrm{MHz})$ & 500 & 500 \\
Range Resolution $(\mathrm{m})$ & 0.3 & 0.3 \\
Antenna beam width, narrow $/$ flood $\left(^{\circ}\right)$ & $5.6 / 7.5$ & $4.3 / 5.8$ \\
Cross-polarization isolation (dB) & $>30$ & $>30$ \\
Transmit/receive polarizations (linear) & $\mathrm{VV}, \mathrm{HH}, \mathrm{VH}, \mathrm{HV}$ & $\mathrm{VV}, \mathrm{HH}, \mathrm{VH}, \mathrm{HV}$ \\
Sensitivity $\left(\mathrm{dB} \mathrm{m}^{2} \mathrm{~m}^{-2}\right)$ & -50 & -50 \\
\hline
\end{tabular}

The power response of the forested and non-forested classes was compared across all the elevation angles for sites 6 and 20 and 9 and 21. These particular pairings were chosen, because they allowed us to observe a forested site immediately adjacent to a non-forested site from one location, under similar conditions. Sites 9 and 21 are the same as sites 6 and 20; however, the snow had been carefully removed from the field of view (FOV), allowing a comparison of both sites with and without snow.

In order to distinguish between the forested and non-forested class within the FOV, a comparison was made of the range profiles across a subset of the incidence angles $\left(34^{\circ}, 40^{\circ}, 46^{\circ}, 49^{\circ}, 55^{\circ}\right.$, and $\left.61^{\circ}\right)$. Due to differing observation parameters, incidence angles of Churchill observations were offset by $-1^{\circ}$ from those of Grand Mesa and TVC. Similarly, the incidence angles of Tobermory observations included $34^{\circ}, 40^{\circ}, 45^{\circ}, 49^{\circ}, 55^{\circ}$, and $60^{\circ}$. These angles were chosen because they were common among all the forested observations. Range profiles, which describe the power response as a function of the range from the antenna, were used to distinguish the forested from the non-forested class by comparing the number of inflection points in each profile. The target profile was manually identified 
for each elevation angle in order to exclude system leakage, which occurs at near range, and random noise, which follows the target signal with power levels at or below $-50 \mathrm{~dB}$. An algorithm comparing the slope of the line between each successive pair of points was then used to identify inflection points along the target profile. The initial and final inflection points, as the range profile transitioned from system leakage to target signal and from the target signal back to noise, were excluded from the tally; therefore, the minimum possible number of inflection points was 1 . Figure 5 provides an example of range profiles for the forested and non-forested classes to illustrate this method.

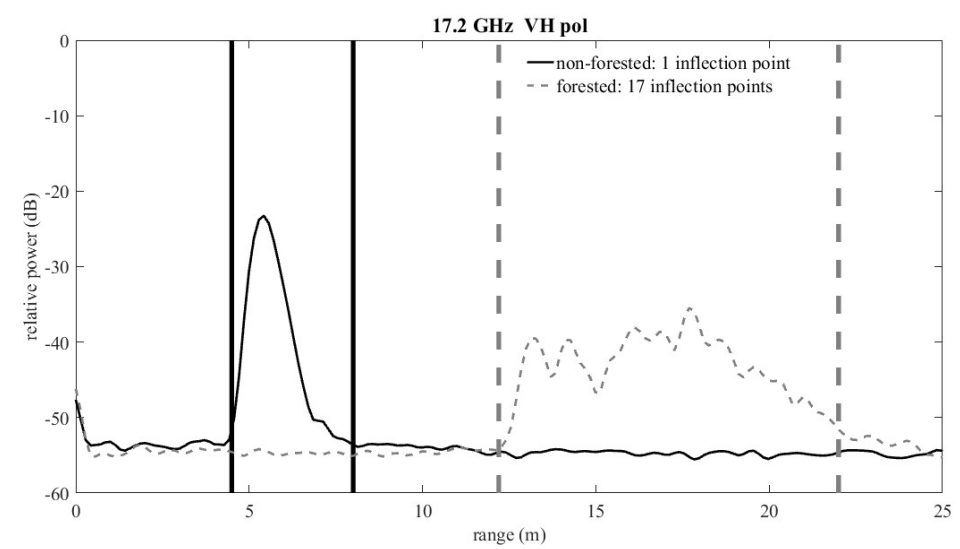

Figure 5. Typical range profiles of non-forested (left) and forested sites (right). Vertical bars bound target profiles, between which inflection points were tallied.

In order to analyze the results of the power response, the Freeman-Durden three-component decomposition [33] was performed on each incidence angle of each scan. The Freeman-Durden three-component decomposition was one of the first model-based decompositions and remains among the simplest; therefore, it was chosen for this study. The model incorporates the measured covariance matrix as a linear combination of three scattering mechanisms: volume scatter from a cloud of randomly oriented dipoles, double-bounce scatter from two orthogonal surfaces, and Bragg scatter from a moderately rough surface $[30,33,50]$. The assumptions of the model include reciprocity, reflection symmetry, and the representation of volume scatterers as a cloud of randomly oriented dipoles $[31,33,34]$. These assumptions are of greater significance at longer wavelengths, such as C-, L-, and P-band, because these will interact with the larger structural components of the forest, such as trunks and large branches, which are neither randomly oriented nor truly symmetrical [30]. At 17.2 $\mathrm{GHz}$ and $9.6 \mathrm{GHz}$, because scattering originates almost entirely from the smaller canopy elements, these assumptions are acceptable. The results of the decomposition were normalized by total power; therefore, each scattering mechanism was described as a proportion of the total power for each elevation angle. This provided greater separation between scattering mechanisms and negated the effects of the decrease in backscattered power, with increasing elevation angles typically observed as compared with the standard Freeman-Durden output, which provides a measure of power for each scattering mechanism. For each site, $V$ was aggregated into the forested and non-forested classes for comparison.

For each of the forested sites, $F F$ was compared with $V_{F D}$. $F F$ was derived from pixel counts of air photos or satellite imagery of forested and non-forested regions within the scatterometer FOV resulting from the image classification. The estimates were calculated for a rectangular area in the FOV of approximately similar size to that scanned with the scatterometer. While the images were not coincident with the radar observations, efforts were made to acquire suitable images as close to the radar observation dates as possible. The images for Churchill and Grand Mesa were acquired from Google Earth and dated July 2014 and June 2016, respectively. An aerial photograph of Tobermory was sourced from the Southwestern Ontario Orthophotography Project (SWOOP) dated April/May 2010. The TVC image was sourced from drone photography in April 2018. 
The in situ field measurements included standard snowpit observations, such as snow depth, density, stratigraphy and temperature profiles [51], and microstructural observations, including a specific surface area [52] and penetration force [53]. Such measurements were necessary in order to understand the microwave response in terms of the physical properties of the target on the ground. Whenever possible, the snowpits were located adjacent to the radar FOV. Nearby weather stations monitored local weather conditions, including air temperature, as shown in Figure $4[54,55]$.

\section{Results and Analysis}

\subsection{Angular Backscatter Response from the Forested and Non-forested Sites}

A minimal difference in backscatter was observed between the forested (S20) and non-forested (S6) sites with snow in Figure 6a, while a greater difference, up to $4.5 \mathrm{~dB}$ and $6 \mathrm{~dB}$ for co- and cross-polarized backscatter, was observed between the forested (S21) and non-forested (S9) sites without snow in Figure 6b; the larger cross-polarized difference was a result of enhanced volume scattering in the forest canopy. Because the SWE at S20 was $48 \mathrm{~mm}$ greater than that at S6, greater backscatter would be expected at the forested site, especially given the larger proportion of wind slab present in the non-forested site, which would have reduced sensitivity to the SWE [56], but this was not the case. This indicated that the forest canopy partially attenuated the signal from the snow beneath. A greater difference in backscatter between snow-on and snow-off conditions was observed at the non-forested site in Figure $6 \mathrm{~d}$ than at the forested site in Figure $6 c$, once again demonstrating the attenuation of the snow signal by the forest canopy. Montomoli et al. [22] also found forests to diminish the sensitivity to the SWE. A stronger backscatter response would therefore be expected from the $202 \mathrm{~mm}$ of the SWE at the forested site (site 20) if the trees were not present, thus leading to a potential underestimation of the SWE, which supports the need for a SWE scaling factor in retrievals over forested landscapes.
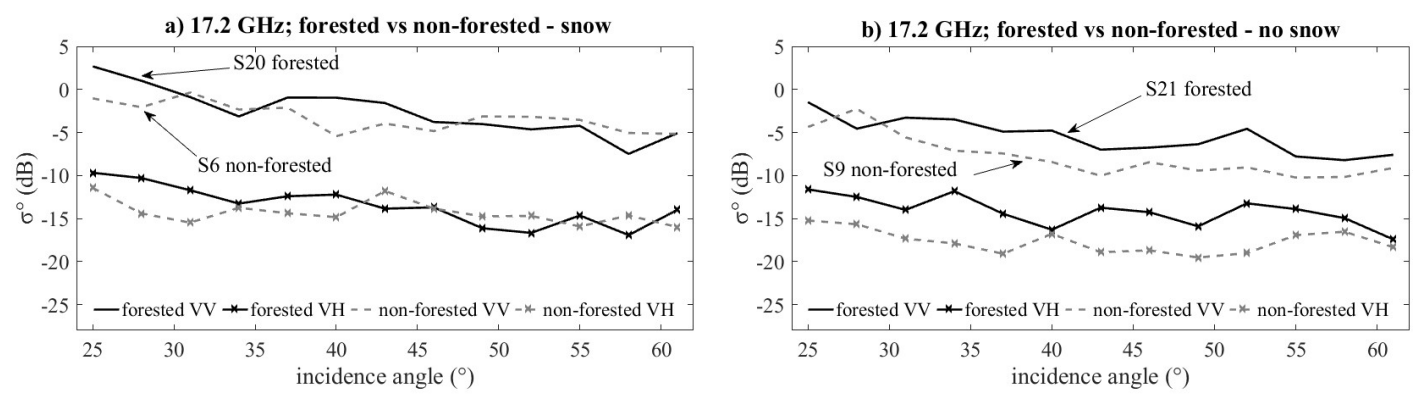

c) $17.2 \mathrm{GHz}$; snow vs no snow - forested
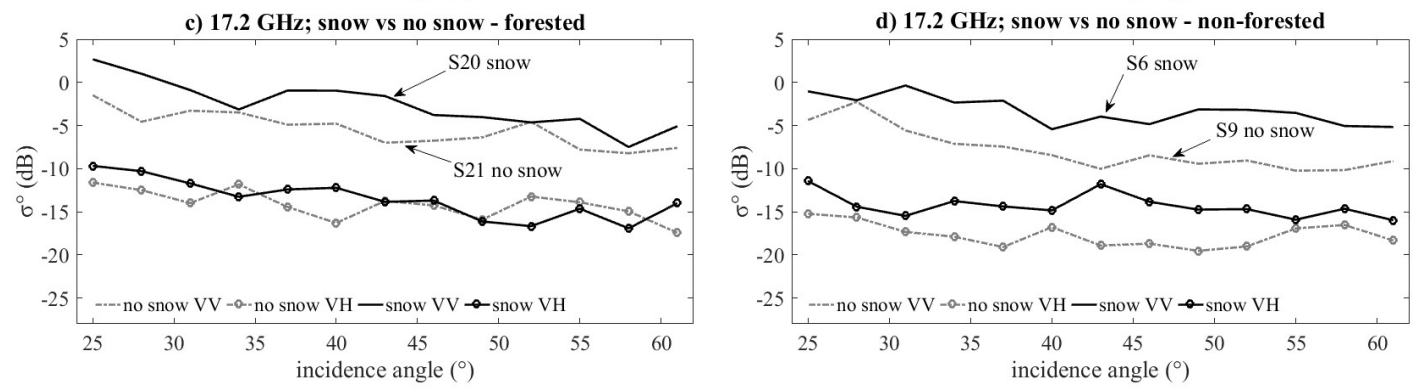

Figure 6. Comparison of $17.2 \mathrm{GHz}$ backscatter response (VV and $\mathrm{VH}$ ) as a function of the incidence angle at the Trail Valley Creek (TVC) and Grand Mesa sites. TVC sites 6 (non-forested [S6]) and 20 (forested [S20]) and sites 9 (non-forested [S9]) and 21 (forested [S21]). The figures compare the 17.2 $\mathrm{GHz}$ responses between the forested and non-forested sites for the (a) snow and (b) no snow cases. Also shown are the 17.2 GHz responses between the snow and no snow sites for the (c) forested and (d) non-forested cases at TVC.

A comparison of the angular response of the forested and non-forested sites at $9.6 \mathrm{GHz}$ is shown, with snow in Figure 7a and without snow in Figure 7b. Across all the elevation angles and polarizations, 
the $9.6 \mathrm{GHz}$ backscatter of the forested site was consistently greater than that of the non-forested site both with and without snow. The greater difference observed in the cross-polarized response once again suggested a volume response from the canopy. Figure $7 \mathrm{c}$,d show the response at $9.6 \mathrm{GHz}$ to the removal of snow in the forested and non-forested sites. Minimal sensitivity to the presence of snow accumulation was observed at both sites. Overall, the observations in Figure 7 show little sensitivity to sub-canopy snow accumulation for this particular forest at $9.6 \mathrm{GHz}$.
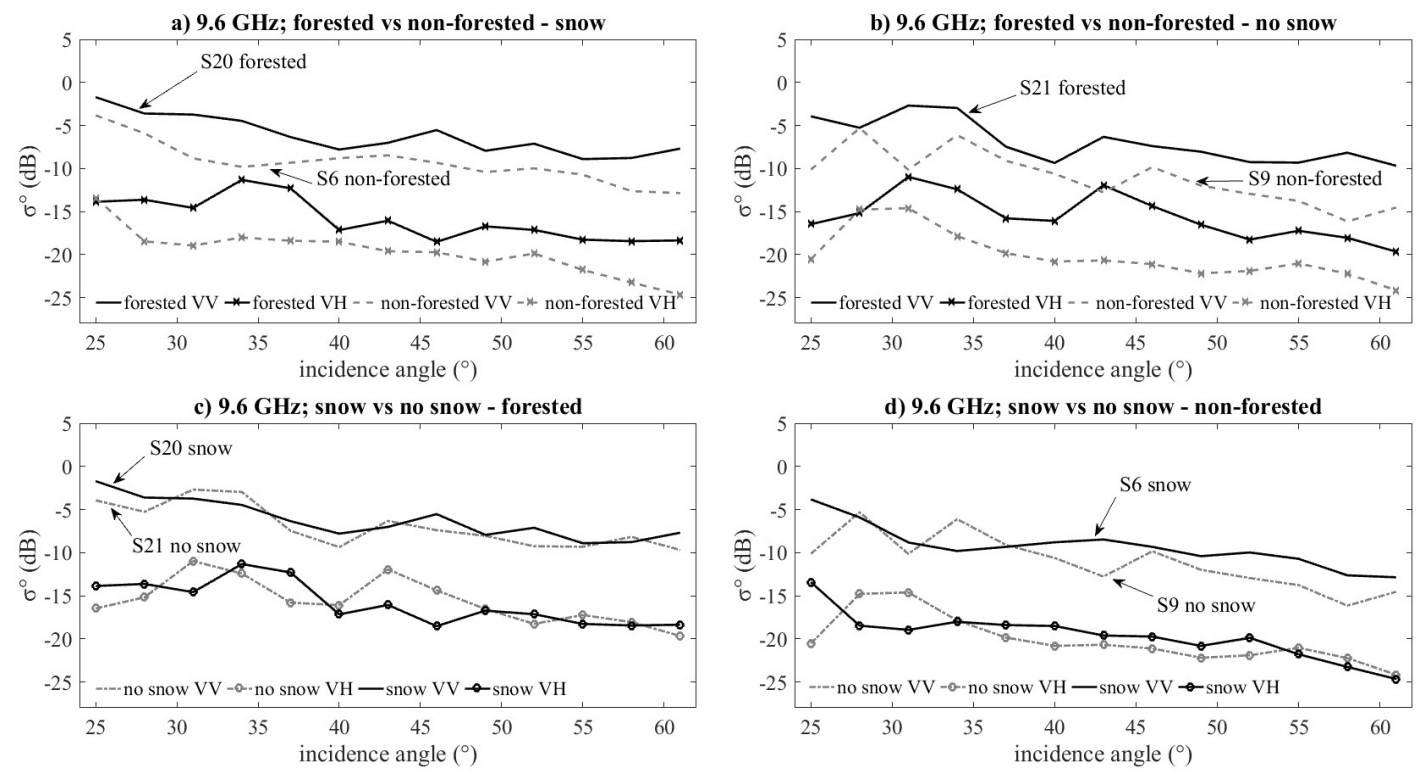

Figure 7. Comparison of $9.6 \mathrm{GHz}$ backscatter response (VV and $\mathrm{VH}$ ) as a function of the incidence angle at the TVC and Grand Mesa sites. TVC sites 6 (non-forested [S6]) and 20 (forested [S20]) and sites 9 (non-forested [S9]) and 21 (forested [S21]). The figures compare the $9.6 \mathrm{GHz}$ responses between the forested and non-forested sites for the (a) snow and (b) no snow cases. Also shown are the $9.6 \mathrm{GHz}$ responses between the snow and no snow sites for (c) forested and (d) non-forested cases at TVC.

These results are important because they illustrate the non-trivial influence of forest on SWE estimates, particularly at $17.2 \mathrm{GHz}$, and highlight the importance of identifying forested areas and accounting for them in SWE retrievals. As such, the presence of even sparse forest could contribute error to SWE estimates if left unaccounted.

\subsection{Range Profile Analysis}

The mean number of inflection points and the standard deviations are provided for range profiles of all the sites and elevation angles in Table 3. The mean number of inflection points was significantly greater in the forested than in the non-forested class, for every combination of frequency, polarization, and elevation angle $(\alpha=0.05)$; across all the observations, the range profiles of the forested class had a mean of 18 inflection points, while that of the non-forested class had a mean of 4 inflection points. The large number of inflection points observed in the forested class indicates higher-order scattering associated with the canopy response at both $17.2 \mathrm{GHz}$ and $9.6 \mathrm{GHz}$. The forested class also had a larger standard deviation in most cases, which was attributed to variation in tree size and canopy density. These results have two important implications: (1) this information could be used to distinguish forested from non-forested environments, and (2) it suggests a useful link between canopy volume and microwave scattering. Site 6 , a non-forested site, was excluded from this analysis due to the inclusion of forest near the edge of the FOV, particularly evident at high incidence angles. 
Table 3. The mean number of inflection points from range profiles.

\begin{tabular}{cccccccc}
\hline & \multirow{2}{*}{$\begin{array}{c}\text { Incidence } \\
\text { Angle }\end{array}$} & \multicolumn{3}{c}{$\mathbf{1 7 . 2} \mathbf{G H z}$} & \multicolumn{3}{c}{$\mathbf{9 . 6} \mathbf{G H z}$} \\
\cline { 2 - 7 } & & $\mathbf{V V}$ & $\mathbf{H H}$ & $\mathbf{V H}$ & $\mathbf{V V}$ & $\mathbf{H H}$ & $\mathbf{V H}$ \\
\hline \multirow{5}{*}{ Forested } & $34^{\circ}$ & $17.2(12.1)$ & $14.7(8.7)$ & $16.8(12.1)$ & $18.4(12.3)$ & $18.5(13.3)$ & $18.4(12.5)$ \\
& $40^{\circ}$ & $16.4(12.5)$ & $16.9(11.1)$ & $15.8(11.3)$ & $20.3(13.3)$ & $21.3(14.1)$ & $20.7(13.6)$ \\
& $46^{\circ}$ & $15.0(9.1)$ & $16.5(9.7)$ & $15.5(12.1)$ & $19.3(13.6)$ & $19.4(14.6)$ & $18.3(13.6)$ \\
& $49^{\circ}$ & $14.2(6.9)$ & $15.0(8.6)$ & $14.5(7.7)$ & $18.0(11.4)$ & $19.5(10.7)$ & $18.1(12.5)$ \\
& $55^{\circ}$ & $17.3(7.5)$ & $17.5(7.8)$ & $18.3(8.3)$ & $20.7(8.1)$ & $19.3(8.3)$ & $19.6(9.1)$ \\
Non-forested & $61^{\circ}$ & $16.5(6.6)$ & $16.6(6.2)$ & $17.8(6.8)$ & $21.0(7.5)$ & $19.6(7.3)$ & $21.3(8.8)$ \\
\hline & $34^{\circ}$ & $4.9(2.3)$ & $5.6(1.3)$ & $4.3(2.3)$ & $4.2(2.0)$ & $4.8(2.2)$ & $3.4(1.7)$ \\
& $40^{\circ}$ & $4.7(1.0)$ & $5.3(1.0)$ & $3.4(2.4)$ & $4.4(1.9)$ & $4.6(2.9)$ & $2.8(1.6)$ \\
& $46^{\circ}$ & $4.1(1.5)$ & $4.0(1.8)$ & $3.3(1.7)$ & $3.4(1.8)$ & $4.0(1.7)$ & $3.2(1.9)$ \\
& $49^{\circ}$ & $4.1(2.4)$ & $4.0(1.5)$ & $3.3(1.4)$ & $3.8(2.2)$ & $3.6(2.1)$ & $3.1(2.2)$ \\
& $55^{\circ}$ & $3.6(2.1)$ & $4.8(1.9)$ & $3.3(2.6)$ & $3.8(2.7)$ & $3.8(2.2)$ & $2.6(1.9)$ \\
& $61^{\circ}$ & $3.8(2.4)$ & $3.5(2.8)$ & $3.4(2.2)$ & $3.3(2.4)$ & $3.5(2.5)$ & $2.9(2.5)$ \\
\hline
\end{tabular}

Note. All the sites included in the calculations. The standard deviation given in brackets.

\subsection{Freeman-Durden Three-Component Decomposition}

Figure 8 shows a comparison of the volume scattering proportion of the decomposition aggregated into the forested and non-forested classes. Volume scattering dominated the forest response, and the difference was found to be significant at both frequencies and all the elevation angles $(\alpha=0.05)$. This is in agreement with the range profile observations, which suggested elevated levels of volume scattering by way of a significantly greater number of inflection points for the forested class. The forested class showed a larger spread in $V_{F D}$, which reflects the variety of forest observed, ranging from a sparse plot of $3 \mathrm{~m}$ black spruce to a dense plot of $15 \mathrm{~m}$ white spruce and white cedar. Site 6 was once again excluded from this analysis due to the inclusion of forest within the FOV.

a) $17.2 \mathrm{GHz}$

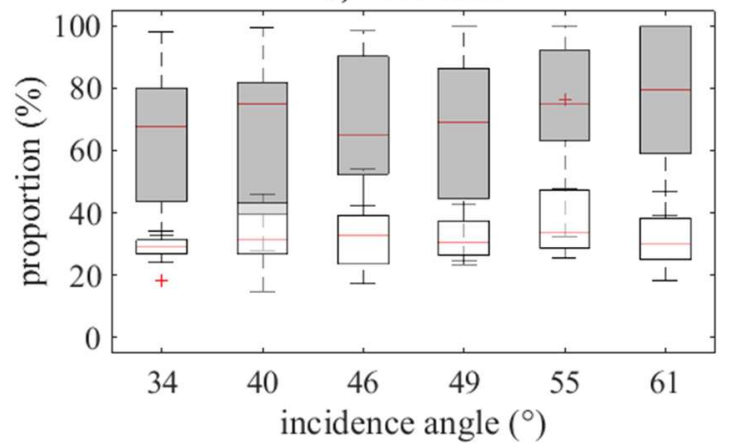

b) $9.6 \mathrm{GHz}$

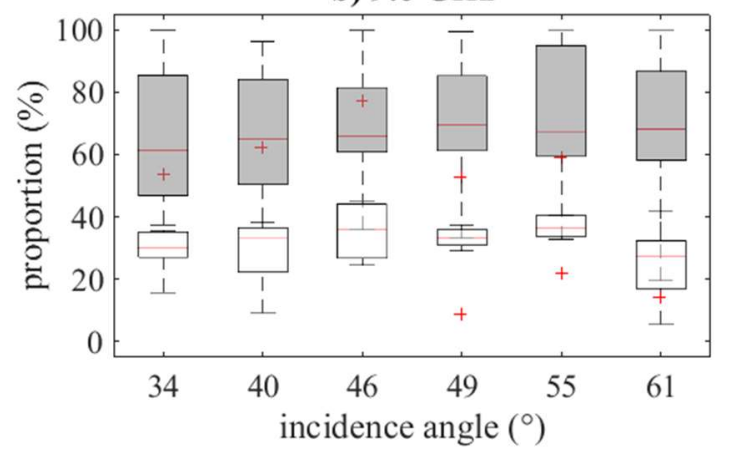

Figure 8. The comparison of the volume scattering proportion for the forested (shaded) and non-forested (white) sites at (a) $17.2 \mathrm{GHz}$, and (b) $9.6 \mathrm{GHz}$.

\subsection{Correlation between Forest Fraction and Volume Scattering}

The results of the FF calculation for each forested site are presented in Table 4 . The Tobermory scene had the highest FF at $84 \%$, followed by Churchill, Grand Mesa, and TVC with FF of $48 \%, 39 \%$, and $16 \%$, respectively. All of the optical images used in calculating FF, except for the TVC image, were acquired in snow-free periods. The area sampled was a function of the radar antenna height in Tobermory and Churchill, where the forested extent was much larger than the radar FOV, and of forest stand dimensions in Grand Mesa and TVC, where the radar FOV was matched to the forested extent. 
Table 4. The results of the forest cover fraction $(F F)$ calculation.

\begin{tabular}{|c|c|c|c|c|c|}
\hline Site & Photo Date & $\begin{array}{l}\text { Area Sampled } \\
\qquad\left(\mathrm{m}^{2}\right)\end{array}$ & $\begin{array}{l}\text { \# of Forest } \\
\text { Pixels }\end{array}$ & $\begin{array}{c}\text { \# of Non-Forest } \\
\text { Pixels }\end{array}$ & $F F(\%)$ \\
\hline Tobermory & May 2010 & 918 & 19720 & 3739 & 84 \\
\hline Churchill & July 2014 & 450 & 4338 & 4638 & 48 \\
\hline Grand Mesa & June 2016 & 252 & 21424 & 33153 & 39 \\
\hline TVC & April 2018 & 25 & 4123 & 22185 & 16 \\
\hline
\end{tabular}

Figures 9 and 10 show the comparison between $F F$ and $V_{F D}$ of the forested sites at $17.2 \mathrm{GHz}$ and $9.6 \mathrm{GHz}$, respectively. There was a strong correlation between $F F$ and $V_{F D}$, particularly at higher elevation angles where $\mathrm{R}=0.93$ at $17.2 \mathrm{GHz}\left(61^{\circ}\right)$ and $\mathrm{R}=0.88$ at $9.6 \mathrm{GHz}\left(55^{\circ}\right)$. All the correlations were significant at the 0.05 level. The strength of the correlation increased with the incidence angle, because at low angles, the radar footprint encountered a treeless gap between the scatterometer and the forest edge at all sites except Tobermory, and so, regardless of $F F$, the microwaves encountered only a small portion of the canopy vegetation. As the incidence angle increased, the microwaves interacted more fully with the canopy. The variation in the volume scattering at each site was due to changes in the tree geometry brought about by wind, snow loading, and other factors that occurred between the acquisition dates. Although there was a strong correlation between $F F$ and volume scattering at these frequencies, it is important to remember that $F F$ is a generalized bulk forest property based on the surface scattering of optical radiation and is not directly linked to the volume of the biomass, but rather to the surfaces exposed to the sensor. However, $V_{F D}$ is a direct result of the microwave interaction with the three-dimensional forest canopy elements, not just its surface. Therefore, $V_{F D}$ provides a more robust representation of the scattering elements than $F F$ in a microwave application. This explains why there was greater variation in $V_{F D}$ than in $F F$. In this way, $V_{F D}$ accounts for the incidence angle and tree geometry and does not require ancillary information or canopy modeling.
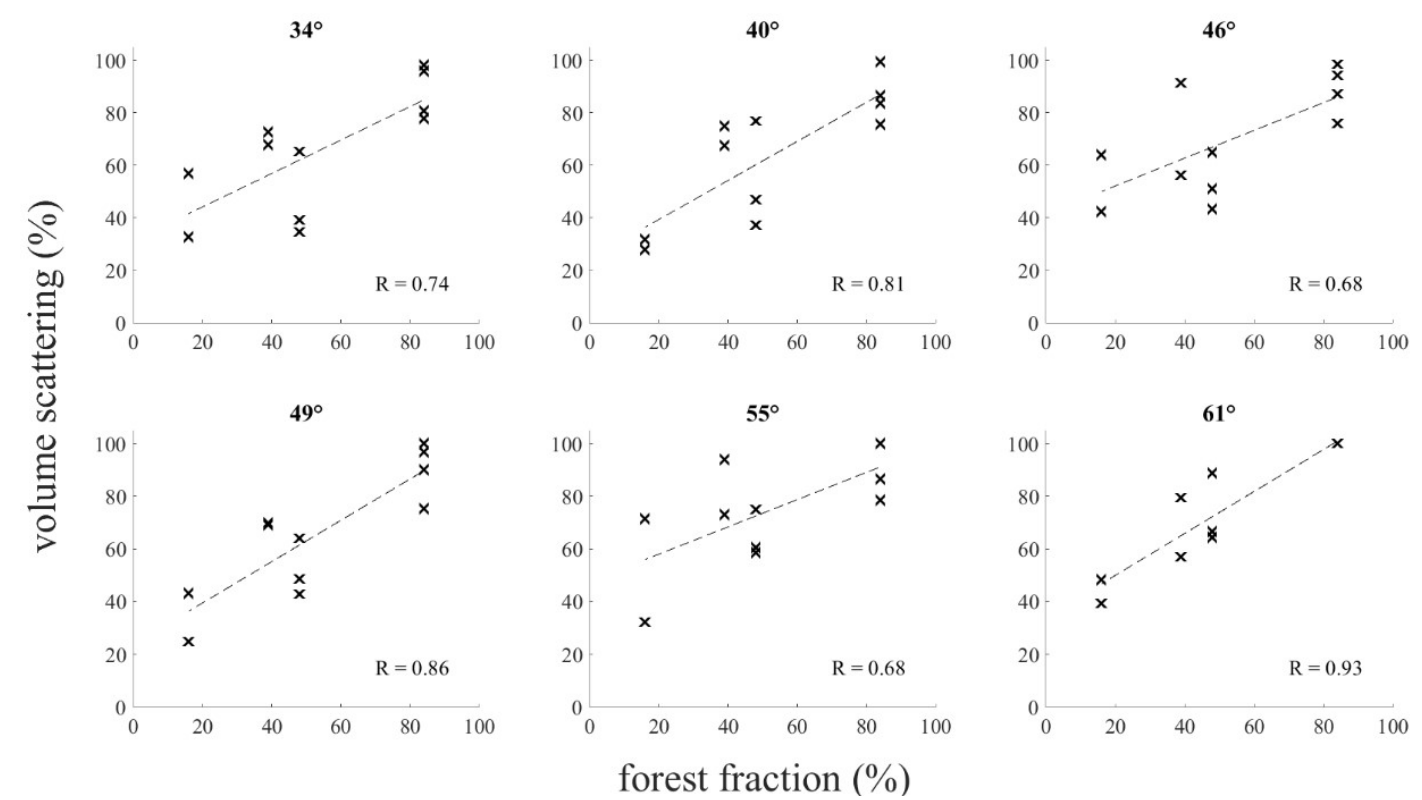

Figure 9. Volume scattering at 17.2 GHz vs. FF for the forested sites at each incidence angle. The line of best fit is for illustrative purposes only. 

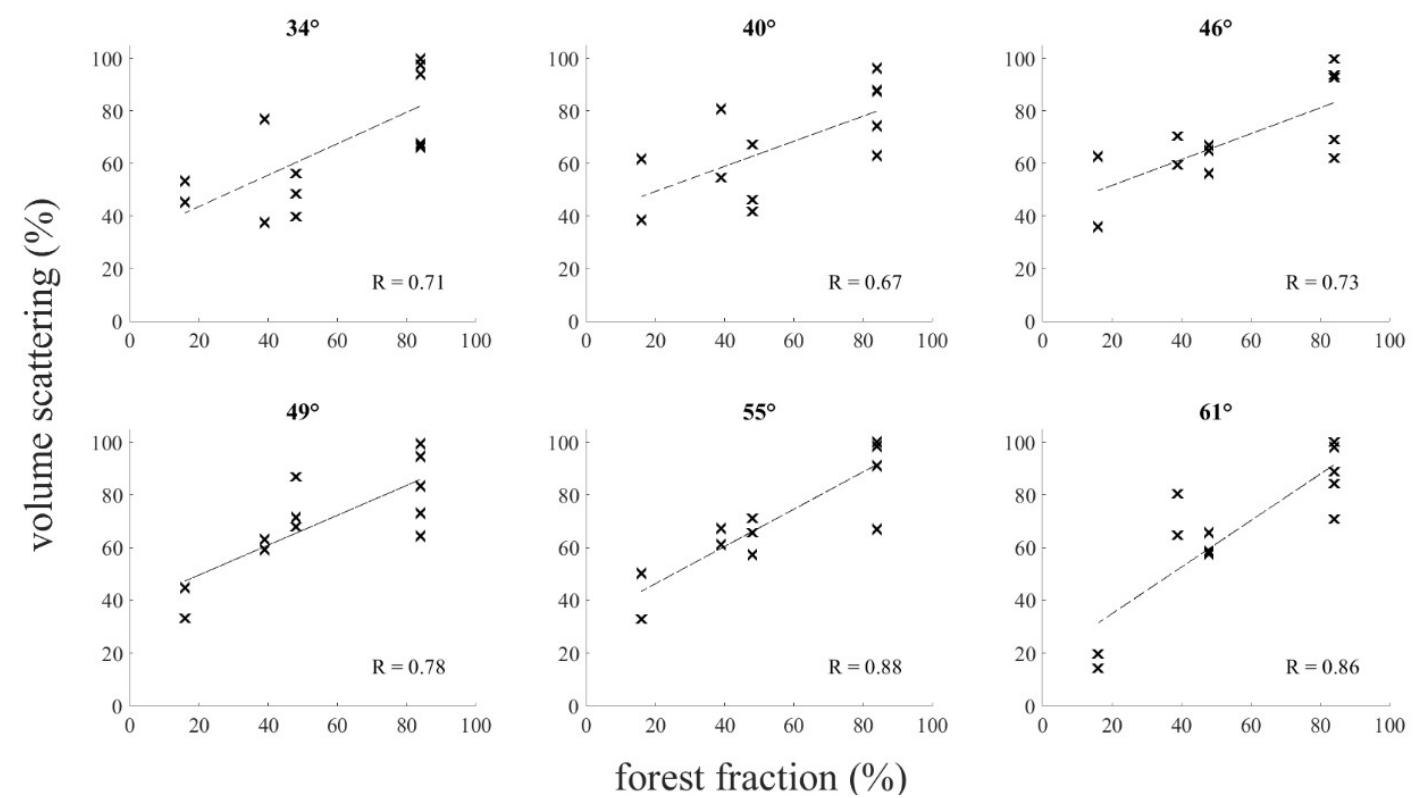

Figure 10. Volume scattering at 9.6 GHz vs. FF for the forested sites at each incidence angle. The line of best fit is for illustrative purposes only.

\section{Implications for SAR-Based SWE Retrievals in Forest-Covered Landscapes}

The scatterometer observations in Sections 4.2 and 4.3 demonstrate the ability to distinguish forested from non-forested landscapes, and either the range profiles or the decomposition results could be used to identify forest. However, the range profile data is not available from a SAR, so only the decomposition results are included in this discussion. For the decomposition approach to be effective, a threshold must be identified, above which, the landscape can be unambiguously identified as forest. Leveraging the strong volume response observed in the forest canopies at both frequencies in Section 4.3, a threshold of $V_{F D} \geq 50 \%$ for forested landscape and $V_{F D}<50 \%$ for non-forested landscape was applied. This simple threshold yields good agreement between the observation and classification of the forested and non-forested classes, with overall accuracies of $87 \%$ and $88 \%$ at $17.2 \mathrm{GHz}$ and 9.6 GHz. Errors in the classification primarily occurred in the low-density stands of TVC, which indicates that with a $F F$ of $16 \%$ or less forests may be undetectable at these frequencies. Error also occurred at low incidence angles in Churchill where gaps were present in the near range of the FOV due to the spacing of the trees. This error was associated with the $30-\mathrm{cm}$ range resolution of UWScat in that the system is sensitive to the presence and absence of individual trees.

Given the strength of correlation between $F F$ and $V_{F D}$, it is apparent these terms contain related information about the forest biomass structure. The performance of $V_{F D}$, when used within the active-microwave model of Equation (1), proposed by [21], in place of $F F$, was evaluated for its ability to retrieve the sub-canopy backscatter determined from the numerical inversion in Equation (2), in which the cost function was minimized in a least squares scheme. The backscatter observations $\left(\sigma_{o b s}^{o}\right)$ at $17.2 \mathrm{GHz}$ from sites 20 and 15 were used to iteratively fit the model against free parameters in the optimization in order to retrieve the sub-canopy signal $\left(\sigma_{\text {snow, }}^{o} P\right)$. Free parameters in the model include the forest canopy backscatter $\left(\sigma_{\text {canopy }}^{o}\right)$, the effective canopy extinction coefficient $\left(K_{e}^{\prime}\right)$, and $\sigma_{\text {snow, } F P}^{o}$. Two-way transmissivity $\left(t_{\text {two-way }}\right)$ is given in Equation (3), as defined by [20], where $K_{e}^{\prime}$ is equivalent to the extinction coefficient $\left(K_{e}\right)$ divided by the cosine of the incidence angle and $F P$ describes the forest parameter used in the model ( $V_{F D}$ or $F F$, in this case). The model's skill at retrieving $\sigma_{\text {snow, } F P}^{o}$ was evaluated, using both $V_{F D}$ and $F F$ as the forest parameter, by comparison with coincident 
observations of adjacent non-forested land (sites 5 and 6), which served as estimates of the true value of the sub-canopy backscatter $\left(\sigma_{\text {obs, snow }}^{o}\right)$.

$$
\begin{gathered}
\sigma_{\text {total }}^{o}=t_{\text {two-way }} \sigma_{\text {snow }, F P}^{o}+\left(1-t_{\text {two-way }}\right) \sigma_{\text {canopy }}^{o} . \\
\min \left\{\sum\left[\sigma_{\text {model }}^{o}\left(\sigma_{\text {snow }, F P}^{o}, \sigma_{\text {canopy }}^{o}, K_{e}^{\prime}, F P\right)-\sigma_{\text {obs }}^{o}\right]^{2}\right\} . \\
t_{\text {two-way }}=e^{-2 K_{e}^{\prime} F P} .
\end{gathered}
$$

The inversion was implemented over the full range of incidence angles from $34^{\circ}$ to $61^{\circ}$ at $17.2 \mathrm{GHz}$ $(\mathrm{VV}, \mathrm{HH}$, and $\mathrm{VH})$, and the summary of results is presented in Figure 11. Note that a different scale was used for $\sigma^{\circ}$ in the top and bottom panels. The observations at site 15 were made from a height of about $9.5 \mathrm{~m}$; thus, the range to target was substantially greater at site 15 than that at site 20, which resulted in a proportionally weaker response due to instrument range limitations. The forest parameters $F F$ and $V_{F D}$ demonstrated similar performance in retrieval of $\sigma_{\text {snow, } F .}^{o}$. A comparison of $\sigma_{\text {snow, } F P}^{o}$, when retrieved using $F F$ and $V_{F D}$, revealed a very strong correlation, while the root-mean-square error (RMSE) values indicated similar performance when compared with $\sigma_{o b s, s n o w}^{o}$. Furthermore, an aggregation of results for all the polarizations, incidence angles, and both sites provided overall RMSE values of 1.79 and 1.80 for $F F$ and $V_{F D}$. The bias, calculated as an average bias of all the incidence angles per site and polarization, was positive in most cases, showing that the retrieval tended to overestimate. Large differences between $\sigma_{\text {snow, } F F}^{0}$ and $\sigma_{\text {snow, }}^{o} V_{F D}$ occurred where there was disagreement between $F F$ and $V_{F D}$. For example, the largest difference $(2.1 \mathrm{~dB})$ occurred at site 15 with $\mathrm{HH}$ polarization and an incidence angle of $58^{\circ}$. This corresponded with an $F F$ of 0.39 and a $V_{F D}$ of $0.81 ; \sigma_{\text {snow }}^{o}, V_{F D}$ was much closer to $\sigma_{o b s^{\prime}}^{o}$ which underscores the utility of $V_{F D}$. Differences between $\sigma_{\text {snow }, F P}^{o}$ and $\sigma_{o b s}^{o}$ were primarily attributed to differences between the sub-canopy environment and the adjacent non-forested land.
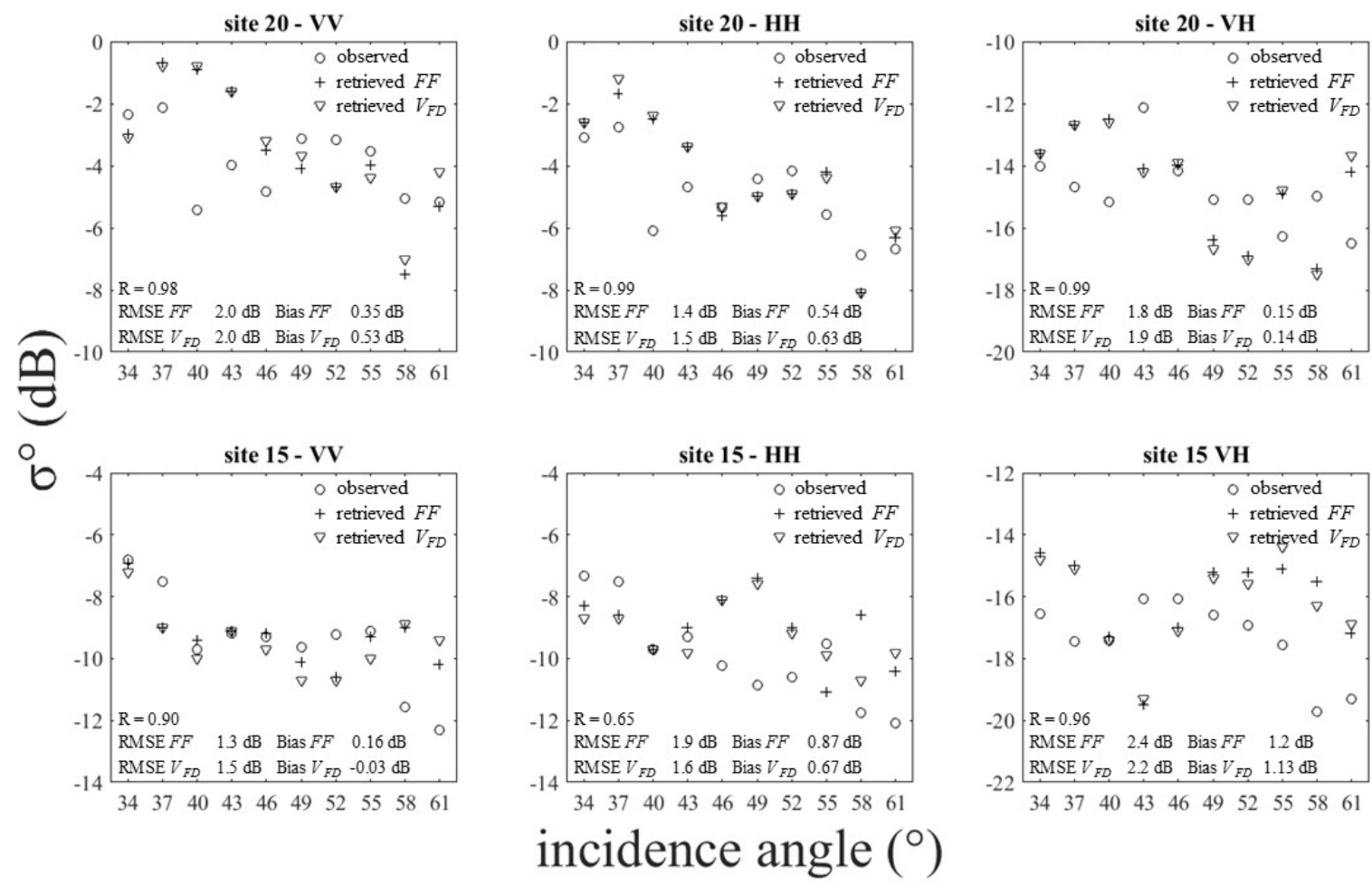

Figure 11. Results of $\sigma_{\text {snow, } F P}^{o}$ retrieval. Retrievals compared with observations from the adjacent non-forested sites. The root-mean-square error (RMSE) and bias were averaged over all the incidence angles. The correlation between $\sigma_{\text {snow }, F F}^{o}$ and $\sigma_{\text {snow }, V_{F D}}^{o}$ is shown. 
Given the similarity in performance between the two forest parameters, these results support the use of $V_{F D}$ for the retrieval of $\sigma_{\text {snow }, F P}^{o}$ from beneath a canopy in place of $F F$. With similar levels of accuracy, the primary benefit of this method remains the ability to retrieve $\sigma_{\text {snow, } F P}^{o}$ without the use of ancillary data. As an additional benefit, given that $K_{e}^{\prime}$ was a free parameter in Equation (2), using $V_{F D}$ as the FP in Equations (1) and (2) allowed for the estimation of forest canopy transmissivity without ancillary data.

\section{Discussion}

The results demonstrate the operational range of these methods for potential use in a SWE retrieval framework. These methods were able to identify forest with $F F>16 \%$, which represents a lower limit of sensitivity for UWScat. An airborne or spaceborne SAR instrument, with a coarser range resolution, may be less sensitive. This classification scheme was based on the average value of $V_{F D}$ across an azimuth sweep, comprised of a varying number of independent samples instead of on a per-pixel basis. While these methods demonstrated the success of this classification scheme, it is recommended that it be repeated with airborne $\mathrm{Ku}$ - and X-band SAR data in order to fully assess the validity of this threshold for discriminating forested landscape.

The upper limit of applicability in dense forest canopy remains; however, these methods will respond to naturally occurring gaps within a forest. If a forest has been identified as being too dense, there will still be occasional gaps in the canopy (e.g., fallen trees, fire damage, etc.), identifiable by a reduction in $V_{F D}$. This method would be successful in retrieving the SWE from within those gaps, providing at least point estimates throughout the otherwise excluded dense forest region.

A limitation, which remains to be investigated, is the response of these methods to a land cover with more complex geometry than that which was observed in this study, including built environments or complex terrain. Depending on their size and structure, these features could influence all three scattering mechanisms, but particularly $V_{F D}$, because it captures all cross-polarized power. Complex man-made structures can cause co- and cross-polarization correlations, which do not normally occur from natural, distributed targets, violating the reflection symmetry assumption, thus artificially inflating $V_{F D}$. Adopting the 4-component method developed by [34], which includes a helical scattering term associated with the scattering matrix of helices or circular polarization states often induced by man-made structures, could allow us to extend the methods in this study to include complex landscapes.

\section{Conclusions}

In this study, UWScat, a ground-based radar scatterometer, was used to observe forested and non-forested landscapes at $9.6 \mathrm{GHz}$ and $17.2 \mathrm{GHz}$ in a selection of terrestrial snow accumulation environments, which included Churchill, Manitoba; Tobermory, Ontario; Grand Mesa, Colorado, and TVC, Northwest Territories. The forest canopy in a snow accumulation environment attenuated backscatter from the sub-canopy snow at $17.2 \mathrm{GHz}$, reducing sensitivity to the SWE. At $9.6 \mathrm{GHz}$, the forested sites consistently produced stronger backscatter than the adjacent non-forested sites, but limited sensitivity to the SWE was observed. A larger difference in the cross-polarized backscatter between the forested and non-forested sites was observed, which suggested an enhanced volume response from the canopy. The forested areas were identifiable by scatterometer range profiles, based on a significant increase in the number of inflection points, and by an increase in the proportion of volume scattering, as determined by the Freeman-Durden three-component decomposition model. A threshold was considered in order to distinguish the forest from the non-forested landscapes, and because range profiles are not available from SAR instruments, only the volume scattering proportion was used. A threshold of $50 \%$ volume scattering was used with good results to distinguish forest. From the results of the decompositions, it was suggested that the volume scattering proportion replace the forest fraction as a means to scale backscatter emanating from the snowpack beneath a canopy in the current SWE retrieval algorithms. This was tested in the retrieval of sub-canopy backscatter using 
the model of [21] and found to have similar performance to the forest fraction. The use of $V_{F D}$ has three distinct advantages: (1) It provides a current, real-time description of the forest condition; (2) It automatically accounts for the incidence angle and canopy structure by providing a description of the scatterers encountered in each case without ancillary information; and (3) It provides coincident information on the forest canopy in remote regions where no forest inventories or models exist. The results of a retrieval of the sub-canopy snow backscatter showed similar accuracy when either $F F$ or $V_{F D}$ were used; however, using $V_{F D}$ should allow for a quicker operationalization of SWE retrieval with minimized complexity and a broader geographical range. An additional benefit of $V_{F D}$ is it can be used within this model to estimate forest canopy transmissivity without ancillary data.

Before these methods are operationalized, some work remains to be completed. In order to use these methods in proximity to a built environment, adjustments to the decomposition should be made, such as those suggested by [30] or [34], to account for the helical polarization state often introduced by irregularly shaped man-made structures. The threshold for distinguishing forest canopy should be tested on an airborne SAR in order to better test the accuracy of the classification, because the scatterometer classification was not pixel-based and included a variable number of samples in each result.

Overall this study demonstrated the sensitivity of $9.6 \mathrm{GHz}$ and $17.2 \mathrm{GHz}$ to a range of forest canopy conditions. These frequencies were shown to provide information linked to both forest biomass and snow accumulation with a useful application in SWE retrieval, which is something not currently possible at other frequencies. It also marked the first use of the Freeman-Durden three-component decomposition of scatterometer data at these frequencies.

Author Contributions: Conceptualization, A.T. and R.K.; methodology, A.T. and R.K.; investigation, A.T. and R.K.; writing-original draft preparation, A.T.; writing-review and editing, R.K.; supervision, R.K.; funding acquisition, R.K.

Funding: This research was funded by NSERC, PCSP, and NSTP.

Acknowledgments: The authors wish to thank NASA for its support during the SnowEx17 field campaign, with special thanks to L. Brucker, K. Elder, and C. Hiemstra for their tremendous efforts. The authors also thank P. Marsh and B. Walker who facilitated the campaign in TVC and provided aerial photographs and meteorological data for that site. Special thanks is given to V. Vanthof for her efforts in the field and the Aurora Research Institute for logistical support. Acknowledgement is given to those involved the data collection during the Can-CSI/CASIX campaign and in Tobermory.

Conflicts of Interest: The authors declare no conflict of interest.

\section{References}

1. Sturm, M.; Goldstein, M.A.; Parr, C. Water and life from snow: A trillion dollar science question. Water Resour. Res. 2017, 53, 2051-2073. [CrossRef]

2. Barnett, T.P.; Adam, J.C.; Lettenmaier, D.P. Potential impacts of a warming climate on water availability in snow-dominated regions. Nature 2005, 438, 303-309. [CrossRef] [PubMed]

3. Derksen, C.; Brown, R. Spring snow cover extent reductions in the 2008-2012 period exceeding climate model projections. Geophys. Res. Lett. 2012, 39, 1-6. [CrossRef]

4. Derksen, C.; Smith, S.L.; Sharp, M.; Brown, L.; Howell, S.; Copland, L.; Mueller, D.R.; Gauthier, Y.; Fletcher, C.G.; Tivy, A.; et al. Variability and change in the Canadian cryosphere. Clim. Chang. 2012, 115, 59-88. [CrossRef]

5. Kunkel, K.E.; Robinson, D.A.; Champion, S.; Yin, X.; Estilow, T.; Frankson, R.M. Trends and extremes in northern hemisphere snow characteristics. Curr. Clim. Chang. Rep. 2016, 2, 65-73. [CrossRef]

6. Brown, R.; Schuler, D.V.; Bulygina, O.; Derksen, C.; Luojus, K.; Mudryk, L.; Wang, L.; Yang, D. Arctic terrestrial snow cover. In Snow, Water, Ice, and Permafrost in the Arctic (SWIPA); Arctic Monitoring and Assessment Programme (AMAP): Oslo, Norway, 2017; pp. 25-64.

7. Rott, H.; Yueh, S.H.; Cline, D.W.; Duguay, C.; Essery, R.; Haas, C.; Hélière, F.; Kern, M.; Macelloni, G.; Malnes, E.; et al. Cold regions hydrology high-resolution observatory for snow and cold land processes. Proc. IEEE 2010, 98, 752-765. [CrossRef] 
8. King, J.M.L.; Kelly, R.; Kasurak, A.; Duguay, C.; Gunn, G.; Mead, J.B. UW-Scat: A ground-based dual-frequency scatterometer for observation of snow properties. IEEE Geosci. Remote Sens. Lett. 2013, 10, 528-532. [CrossRef]

9. King, J.; Kelly, R.; Kasurak, A.; Duguay, C.; Gunn, G.; Rutter, N.; Watts, T.; Derksen, C. Spatio-temporal influence of tundra snow properties on Ku-band (17.2 GHz) backscatter. J. Glaciol. 2015, 61, 267-279. [CrossRef]

10. Chang, W.; Tan, S.; Lemmetyinen, J.; Tsang, L.; Xu, X.; Yueh, S.H. Dense media radiative transfer applied to SnowScat and SnowSAR. IEEE J. Sel. Top. Appl. Earth Obs. Remote Sens. 2014, 7, 3811-3825. [CrossRef]

11. Leinss, S.; Wiesmann, A.; Lemmetyinen, J.; Hajnsek, I. Snow water equivalent of dry snow measured by differential interferometry. IEEE J. Sel. Top. Appl. Earth Obs. Remote Sens. 2015, 8, 3773-3790. [CrossRef]

12. Xiong, C.; Shi, J.; Lemmetyinen, J. Refinement of the $\mathrm{X}$ and $\mathrm{Ku}$ band dual-polarization scatterometer snow water equivalent retrieval algorithm. In Proceedings of the 2014 IEEE Geoscience and Remote Sensing Symposium, Quebec City, QC, Canada, 13-18 July 2014; pp. 2419-2422. [CrossRef]

13. Cui, Y.; Xiong, C.; Lemmetyinen, J.; Shi, J.; Jiang, L.; Peng, B.; Li, H.; Zhao, T.; Ji, D.; Hu, T. Estimating snow water equivalent with backscattering at $\mathrm{X}$ and $\mathrm{Ku}$ band based on absorption loss. Remote Sens. 2016, 8, 505. [CrossRef]

14. Zhu, J.; Tan, S.; King, J.; Derksen, C.; Lemmetyinen, J.; Tsang, L. Forward and inverse radar modeling of terrestrial snow using SnowSAR data. IEEE Trans. Geosci. Remote Sens. 2018, 56, 1-11. [CrossRef]

15. Sturm, M.; Durand, M.; Robinson, D.; Serreze, M. Got Snow? The Need to Monitor Earth's Snow Resources; NASA: Boulder, CO, USA, 2015.

16. Brandt, J.P.; Flannigan, M.D.; Maynard, D.G.; Thompson, I.D.; Volney, W.J.A. An introduction to Canada's boreal zone: Ecosystem processes, health, sustainability, and environmental issues 1. Environ. Rev. 2013, 21, 207-226. [CrossRef]

17. Sturm, M.; Holmgren, J.; Liston, G. A seasonal snow cover classification system for local to global applications. J. Clim. 1995, 8, 1261-1283. [CrossRef]

18. Macelloni, G.; Brogioni, M.; Montomoli, F.; Fontanelli, G. Effect of forests on the retrieval of snow parameters from backscatter measurements. Eur. J. Remote Sens. 2012, 45, 121-132. [CrossRef]

19. Macelloni, G.; Brogioni, M.; Montomoli, F.; Paloscia, S.; Lemmetyinen, J.; Pulliainen, J.; Rott, H. Monitoring snow parameters in boreal forest using multi-frequency SAR data. In Proceedings of the 2014 XXXIth URSI General Assembly and Scientific Symposium (URSI GASS), Beijing, China, 16-23 August 2014; pp. 4-6. [CrossRef]

20. Montomoli, F.; Macelloni, G.; Brogioni, M.; Lemmetyinen, J.; Rott, H. Estimation of vegetation and soil backscattering for the retrieval of SWE in sparse forests. In Proceedings of the 2015 IEEE International Geoscience and Remote Sensing Symposium (IGARSS), Milan, Italy, 26-31 July 2015; pp. 1602-1605. [CrossRef]

21. Cohen, J.; Lemmetyinen, J.; Pulliainen, J.; Heinila, K.; Montomoli, F.; Seppanen, J.; Hallikainen, M.T. The effect of boreal forest canopy in satellite snow mapping-A multisensor analysis. IEEE Trans. Geosci. Remote Sens. 2015, 53, 6593-6607. [CrossRef]

22. Montomoli, F.; Macelloni, G.; Brogioni, M.; Lemmetyinen, J.; Cohen, J.; Rott, H. Observations and simulation of multifrequency SAR data over a snow-covered boreal forest. IEEE J. Sel. Top. Appl. Earth Obs. Remote Sens. 2016, 9, 1216-1228. [CrossRef]

23. Ulaby, F.T.; Sarabandi, K.; McDonald, K.; Whitt, M.; Craig Dobson, M. Michigan microwave canopy scattering model. Int. J. Remote Sens. 1990, 11, 1223-1253. [CrossRef]

24. Le Toan, T.; Beaudoin, J.R.; Guyon, D. Relating forest biomass to SAR data. IEEE Trans. Geosci. Remote Sens. 1992, 30, 403-411. [CrossRef]

25. Dobson, M.C.; Ulaby, F.T.; Le Toan, T.; Beaudoin, A.; Kasischke, E.S.; Christensen, N. Dependence of radar backscatter on coniferous forest biomass. IEEE Trans. Geosci. Remote Sens. 1992, 30, 412-415. [CrossRef]

26. Dobson, M.C.; Pierce, L.; Sarabandi, K.; Ulaby, F.T.; Sharik, T. Preliminary analysis of ERS-1 SAR for forest ecosystem studies. IEEE Trans. Geosci. Remote Sens 1992, 30, 203-211. [CrossRef]

27. Mougin, E.; Lopes, A.; Karam, M.A.; Fung, A.K. Effect of tree structure on X band microwave signature of conifers. IEEE Trans. Geosci. Remote Sens. 1993, 31, 655-667. [CrossRef]

28. Dobson, M.C.; Ulaby, F.; Pierce, L. Land-cover classification and estimation of terrain attributes using synthetic aperture radar. Remote Sens. Environ. 1995, 51, 199-214. [CrossRef] 
29. Durden, S.L.; Van Zyl, J.J.; Zebker, H.A. Modeling and observation of the radar polarization signature of forested areas. IEEE Trans. Geosci. Remote Sens. 1989, 27, 290-301. [CrossRef]

30. Arii, M.; Van Zyl, J.J.; Kim, Y. Adaptive model-based decomposition of polarimetric SAR covariance matrices. IEEE Trans. Geosci. Remote Sens. 2011, 49, 1104-1113. [CrossRef]

31. Antropov, O.; Rauste, Y.; Hame, T. Volume scattering modeling in PolSAR decompositions: Study of ALOS PALSAR data over boreal forest. IEEE Trans. Geosci. Remote Sens. 2011, 49, 3838-3848. [CrossRef]

32. Magagi, R.; Bernier, M.; Ung, C.H. Quantitative analysis of RADARSAT SAR Data over a sparse forest canopy. IEEE Trans. Geosci. Remote Sens. 2002, 40, 1301-1313. [CrossRef]

33. Freeman, A.; Durden, S.L. A three-component scattering model for polarimetric SAR data. IEEE Trans. Geosci. Remote Sens. 1998, 36, 963-973. [CrossRef]

34. Yamaguchi, Y.; Ishido, M.; Yamada, H.; Moriyama, T. A four-component decomposition of POLSAR image. Int. Geosci. Remote Sens. Symp. 2005, 6, 4073-4076. [CrossRef]

35. Freeman, A. Fitting a two-component scattering model to polarimetric SAR data from forests. IEEE Trans. Geosci. Remote Sens. 2007, 45, 2583-2592. [CrossRef]

36. Hajnsek, I.; Jagdhuber, T.; Schön, H.; Papathanassiou, K.P. Potential of estimating soil moisture under vegetation cover by means of PolSAR. IEEE Trans. Geosci. Remote Sens. 2009, 47, 442-454. [CrossRef]

37. An, W.; Cui, Y.; Yang, J. Three-component model-based decomposition for polarimetric SAR data. IEEE Trans. Geosci. Remote Sens. 2010, 48, 2732-2739. [CrossRef]

38. Van Zyl, J.J.; Arii, M.; Kim, Y. Model-based decomposition of polarimetric SAR covariance matrices constrained for nonnegative eigenvalues. IEEE Trans. Geosci. Remote Sens. 2011, 49, 3452-3459. [CrossRef]

39. Kelly, R.; Thompson, A. SnowEx17 Ground-Based UWScat Ku-and X-Band Frequency Modulated Continuous Wave Radar, Version 1.; NASA National Snow and Ice Data Center Distributed Active Archive Center: Boulder, CO, USA, 2018.

40. Western Regional Climate Centre (WRCC). Mesa Lakes Resort, Colorado. Available online: https://wrcc.dri. edu/cgi-bin/cliMAIN.pl?co5520 (accessed on 10 August 2018).

41. United States Department of Agriculture (USDA). Natural Resources Conservation Service, Soils. Web soil Survey. Available online: https://websoilsurvey.sc.egov.usda.gov/App/HomePage.htm (accessed on 1 August 2018).

42. Environment and Climate Change Canada (ECCC). Canadian Climate Normals 1981-2010 Station Data-Inuvik A Northwest Territories. Available online: https:/ / bit.ly/2GFYkdR (accessed on 3 September 2018).

43. Marsh, P.; Pomeroy, J. Meltwater fluxes at an Arctic forest-tundra site. Hydrol. Process. 1996, 10, 1383-1400. [CrossRef]

44. Pohl, S.; Davison, B.; Marsh, P.; Pietroniro, A. Modelling spatially distributed snowmelt and meltwater runoff in a small arctic catchment with a hydrology land-surface scheme (WATCLASS). Atmos.-Ocean 2005, 43, 193-211. [CrossRef]

45. Environment and Climate Change Canada (ECCC). Canadian Climate Normals 1981-2010 Station Data-Churchill A Manitoba. Available online: https:/ / bit.ly/2LoH631 (accessed on 3 September 2018).

46. Peter Kershaw, G.; McCulloch, J. Midwinter snowpack variation across the Arctic treeline, Churchill, Manitoba, Canada. Arct. Antarct. Alp. Res. 2007, 39, 9-15. [CrossRef]

47. Environment and Climate Change Canada (ECCC). Canadian Climate Normals 1981-2010 Station Data-Wiarton A Ontario. Available online: https:/ / bit.ly /2QYA5LR (accessed on 3 September 2018).

48. Canadian Soil Information Service (CanSIS). Soil Survey of Bruce County (Report No. 16 of the Ontario Soil Survey). Available online: https:/ / bit.ly/2EzxXDJ (accessed on 3 September 2018).

49. Sekelsky, S.M. Near-field reflectivity and antenna boresight gain corrections for millimeter-wave atmospheric radars. Am. Met. Soc. 2002, 19, 468-477. [CrossRef]

50. Freeman, A.; Durden, S.L. A three-component scattering model to describe polarimetric SAR data. Proc. SPIE 1748 Radar Polarim. 1993, 1748, 213-224. [CrossRef]

51. Elder, K.; Brucker, L.; Hiemstra, C.; Marshall, H. SnowEx17 Community Snow Pit Measurements, Version 1; NASA National Snow and Ice Data Center Distributed Active Archive Center: Boulder, CO, USA, 2018.

52. Rutter, N.; Pan, J.; Durand, M.; King, J.; Derksen, C.; Larue, F. SnowEx17 Laser Snow Microstructure Specific Surface Area Data, Version 1; NASA National Snow and Ice Data Center Distributed Active Archive Center: Boulder, CO, USA, 2018. 
53. Derksen, C.; Teich, M.; Brady, M.; King, J. SnowEx17 SnowMicroPen (SMP) Raw Penetration Force Profiles, Version 1; NASA National Snow and Ice Data Center Distributed Active Archive Center: Boulder, CO, USA, 2017.

54. Environment and Climate Change Canada (ECCC). Historical Data. Available online: https://bit.ly/2JjRnPp (accessed on 5 July 2018).

55. NASA. SnowEx17 Meteorological Station Data (Mesa West); 2017.

56. King, J.; Derksen, C.; Toose, P.; Langlois, A.; Larsen, C.; Lemmetyinen, J.; Marsh, P.; Montpetit, B.; Roy, A.; Rutter, N.; et al. The influence of snow microstructure on dual-frequency radar measurements in a tundra environment. Remote Sens. Environ. 2018, 215, 242-254. [CrossRef] 